\title{
ANATOMIA DE ALGUMAS ESPÉCIES AQUÁTICAS DE ERIOCAULACEAE BRASILEIRAS
}

\author{
Alessandra Ike Coan ${ }^{1}$ \\ Vera Lucia Scatena ${ }^{1}$ \\ Ana Maria Giulietti ${ }^{2}$
}

Recebido em 28/08/2001. Aceito em 12/03/2002.

\begin{abstract}
RESUMO - (Anatomia de algumas espécies aquáticas de Eriocaulaceae brasileiras). Estudou-se a anatomia de raízes, caules, folhas e escapos de Eriocaulon elichrysoides, Leiothrix fluitans, Paepalanthus obtusifolius, Philodice hoffmannseggii, Syngonanthus caulescens e Tonina fluviatilis, espécies aquáticas de Eriocaulaceae que ocorrem em diferentes ecossistemas brasileiros, visando a caracterização anatômica das mesmas e também a interpretação das adaptações ao ambiente. Essas plantas caracterizam-se por apresentarem raízes com aspecto esponjoso e esbranquiçado; acúmulo de ar no córtex; epiderme unisseriada, de paredes finas; córtex externo, mediano e interno; endoderme unisseriada e periciclo unisseriado ou multisseriado. Em L. fluitans, P. obtusifolius e T. fluviatilis foram observadas raízes absorventes com aerênquima e raízes fixadoras sem aerênquima. Caules aéreos ou rizomatosos, com ou sem espessamentos causados pelo periciclo. Folhas e escapos com células epidérmicas de paredes finas, estômatos somente na face abaxial, parênquima clorofiliano frouxo, tecido de sustentação pouco desenvolvido e feixes vasculares colaterais. Essas estruturas anatômicas são típicas de plantas de ambientes úmidos ou aquáticos, e ocorrem de forma convergente em diferentes gêneros de Eriocaulaceae.
\end{abstract}

Palavras-chave - Anatomia, Eriocaulaceae brasileiras, hidrofitismo, órgãos vegetativos

\begin{abstract}
Anatomy of some aquatic species of the Brazilian Eriocaulaceae). The anatomy of roots, stems, leaves, and scapes of Eriocaulon elichrysoides, Leiothrix fluitans, Paepalanthus obtusifolius, Philodice hoffmannseggii, Syngonanthus caulescens, and Tonina fluviatilis were studied. All species are aquatic Eriocaulaceae that occur in Brazilian ecosystems. This paper aims to describe the anatomical characterization as well as the interpretation of the adaptations related to the environment. These species present roots with spongy and whitish aspect; air storage in the cortex; thin-walled uniseriate epidermal cells; differentiated cortex; uniseriate endodermis, and uniseriate or multiseriate pericycle. L. fluitans, P. obtusifolius, and T. fluviatilis present roots that store and roots that do not store air in the cortex. The stems are aerial or rhizomatous, with or without thickening resulted from the activity of the pericycle. Leaves and scapes present thin-walled epidermal cells, stomata on the abaxial surface, loosely aggregated chlorenchyma, reduced collenchyma, and collateral vascular bundles. The anatomical features observed are those typical of plants of aquatic or wet habitats. They are convergent and occur in different genera of Eriocaulaceae.
\end{abstract}

Key words - Anatomy, brazilian Eriocaulaceae, hydrophytism, vegetative organs

\footnotetext{
${ }^{1}$ Instituto de Biociências, Universidade Estadual Paulista - UNESP, Caixa Postal 199, 13506-900 - Rio Claro, São Paulo, Brasil. Bolsistas CNPq (aleike@ @otmail.com - autor para correspondência)

${ }^{2}$ Departamento de Ciências Biológicas, Universidade Federal de Feira de Santana, BR 116, km 3, 44031-460 - Feira de Santana, Bahia, Brasil. Bolsista CNPq
} 


\section{Introdução}

A família Eriocaulaceae apresenta 10 gêneros e cerca de 1200 espécies que se distribuem nas regiões tropicais e subtropicais do mundo (Giulietti \& Hensold 1990). A maioria das espécies da família (entre 600-700 espécies) ocorre nos Campos Rupestres do Brasil (Giulietti et al. 1987).

As Eriocaulaceae reúnem plantas que possuem diferentes hábitos, variando desde alguns milímetros até dois metros de altura (Giulietti et al. 1995), ocorrendo nos mais diversos habitats, desde ambientes xerofíticos até ambientes aquáticos ou anfíbios (semiaquáticos) (Tomlinson 1969). A maioria das espécies da família ocorre em solos arenosos e/ ou pedregosos, úmidos ou secos, de $\mathrm{pH}$ ácido; porém, algumas espécies dos diferentes gêneros são aquáticas ou crescem em locais pantanosos (Giulietti \& Hensold 1990).

$\mathrm{O}$ gênero Eriocaulon inclui cerca de 450 espécies e a grande maioria das espécies é aquática com as folhas total ou parcialmente submersas, sendo o único gênero com distribuição pantropical, com algumas espécies crescendo em climas temperados (Ruhland 1903). Segundo Scatena et al. (1999) elas ocupam as margens de riachos ou lagoas temporárias.

Paepalanthus inclui cerca de 400 espécies que podem ocorrer em diferentes habitats, variando desde solos arenosos úmidos ou secos, até sobre pedras (Scatena et al. 1998), distribuindo-se na África e nas Américas Central e do Sul (Giulietti \& Hensold 1990).

$\mathrm{O}$ gênero Philodice inclui apenas duas espécies, das quais, Ph. hoffmannseggii Mart. apresenta maior distribuição, ocorrendo disjuntamente na Venezuela e no Brasil em solos arenosos úmidos (Giulietti \& Hensold 1990). Tonina é um gênero monoespecífico incluindo apenas T. fluviatilis Aubl., espécie aquática ou anfíbia, com ampla distribuição geográfica, ocorrendo desde na América Central até no Brasil (Giulietti \& Hensold 1990), onde é restrita às margens e interior de riachos rasos ou pequenas lagoas, principalmente nas regiões litorâneas do Norte ao Sudeste do país.

O gênero Leiothrix inclui cerca de 37 espécies, é restrito à América do Sul e as espécies crescem em diferentes habitats (Giulietti \& Hensold 1990), sendo L. fluitans (Mart.) Ruhland a única espécie aquática (Ruhland 1903).

As espécies do gênero Syngonanthus ocorrem em diferentes habitats que podem variar desde solos arenosos secos a brejosos, ou margens de rios (Lazzari 1995). Esse gênero distribui-se na África e nas Américas, principalmente na América do Sul (Giulietti \& Hensold 1990). S. caulescens (Poir.) Ruhland possui a maior distribuição geográfica do gênero, provavelmente associada ao hábito aquático (Giulietti \& Pirani 1988).

Tendo em vista que menos de $20 \%$ das espécies brasileiras de Eriocaulaceae ocorrem como aquáticas ou anfíbias e que tais plantas pertencem a diferentes gêneros, esse trabalho teve como objetivo a caracterização anatômica desse grupo, tentando interpretar as estruturas anatômicas encontradas com relação ao ambiente aquático ou com as relações filogenéticas nos gêneros.

\section{Material e métodos}

O material foi coletado e fixado durante excursões realizadas em diferentes áreas e ecossistemas do Brasil. Eriocaulon elichrysoides Bong. BRASIL. Minas Gerais: Santana do Riacho, Serra do Cipó, Scatena et al. 183 (HRCB) - planta aquática nas margens ou extensão de riacho - ecossistema campo rupestre. Leiothrix fluitans (Mart.) Ruhland. BRASIL. Minas Gerais: Santana do Riacho, Serra do Cipó, Giulietti CFSC 5051 (SPF) planta aquática presa diretamente sobre o leito (em cachoeira ou não) de riachos - ecossistema 
campo rupestre. Paepalanthus obtusifolius (Stand.) Koern. BRASIL. Bahia: Rio de Contas, estrada entre Rio de Contas e o Pico das Almas, Harley et al. 19812 (HUEFS) planta aquática ou anfíbia em riacho ecossistema campo rupestre. Philodice hoffmannseggii Mart. BRASIL. Mato Grosso: Nova Chavantina, Câmpus da UEMT, Giulietti 1381 (HUEFS) - planta aquática ou anfíbia em lagoa - ecossistema cerradão. Syngonanthus caulescens (Poir.) Ruhl. BRASIL. Minas Gerais: Santana do Riacho, Serra do Cipó, Scatena et al. 114 (HRCB) planta aquática, raramente anfíbia em riachos - ecossistema campo rupestre. Tonina fluviatilis Aubl. BRASIL. Pernambuco: Recife, Mata Dois Irmãos, Alves \& Pinto s.n. (HRCB 26546) - planta aquática em riachos ou lagoas - ecossistema mata atlântica.

O estudo anatômico das raízes, caules, folhas e escapos efetuou-se a partir de material fixado em FAA 50 (Johansen 1940). As peças das regiões medianas dos órgãos de pelo menos quatro indivíduos de cada espécie foram submetidas à desidratação em série etílica e à infiltração em historresina (glicol metacrilato - JB4/Polysciences), seguida da inclusão (Feder \& O’Brien 1968). O material incluído foi seccionado no micrótomo rotativo Reichert-Jung, modelo 2040, com 5$10 \mathrm{~mm}$ de espessura. Os cortes anatômicos obtidos foram corados com Azul de Toluidina (Feder \& O’Brien 1968) e montados em lâminas permanentes com resina sintética (Entellan).

Algumas secções anatômicas foram realizadas à mão livre nas regiões medianas dos órgãos, com o auxílio de lâminas de barbear, coradas com fucsina e azul de astra (Roeser 1962) e montadas em gelatina glicerinada entre lâmina e lamínula. As fotografias foram realizadas ao fotomicroscópio Olympus, modelo PM-20, com projeção da escala micrométrica.

\section{Resultados}

Raízes - Todas as espécies estudadas apresentam raízes que acumulam ar no córtex (Fig. 1-5, 7). Apresentam epiderme formada por uma única camada de células de paredes finas. A exoderme é unisseriada com células de paredes levemente espessadas (Fig. 7, 9).

O parênquima cortical é dividido em três zonas distintas: o córtex externo - formado pela exoderme; o córtex médio - constituído por células braciformes de paredes levemente espessadas, que se comunicam em diferentes planos (Fig. 2), e por células de paredes finas que se desintegram (Fig. 3-5), formando espaços que reservam ar; e o córtex interno - formado por número variado de camadas de células geralmente arredondadas, com espaços intercelulares reduzidos (Fig. 1, 3-5). Entre as células braciformes do parênquima cortical, ocorrem células maiores, de paredes finas, cujas paredes transversais e tangenciais se rompem resultando espaços que reservam ar, denominados de aerênquimas lisígenos, decorrentes da quebra das paredes celulares (Fig. 4-5 - setas).

P. obtusifolius (Fig. 5-6), T. fluviatilis (Fig. 7-8) e L. fluitans (Fig. 9-10) apresentam dois tipos distintos de raízes no mesmo indivíduo: as raízes basais - localizadas na extremidade inferior da planta, que são principalmente absorventes, com aerênquima ou espaços intercelulares conspícuos, e as raízes adventícias - localizadas ao longo de todo o caule, que são principalmente fixadoras, sem aerênquima ou espaços intercelulares consideráveis. As raízes adventícias são mais finas e de coloração marrom, quando comparadas com as basais que são mais espessas e esbranquiçadas. Também apresentam estrutura interna diferenciada pela ausência de exoderme, pela presença de córtex constituído apenas por células isodiamétricas e pela presença de cilindro vascular reduzido nas raízes adventícias. 


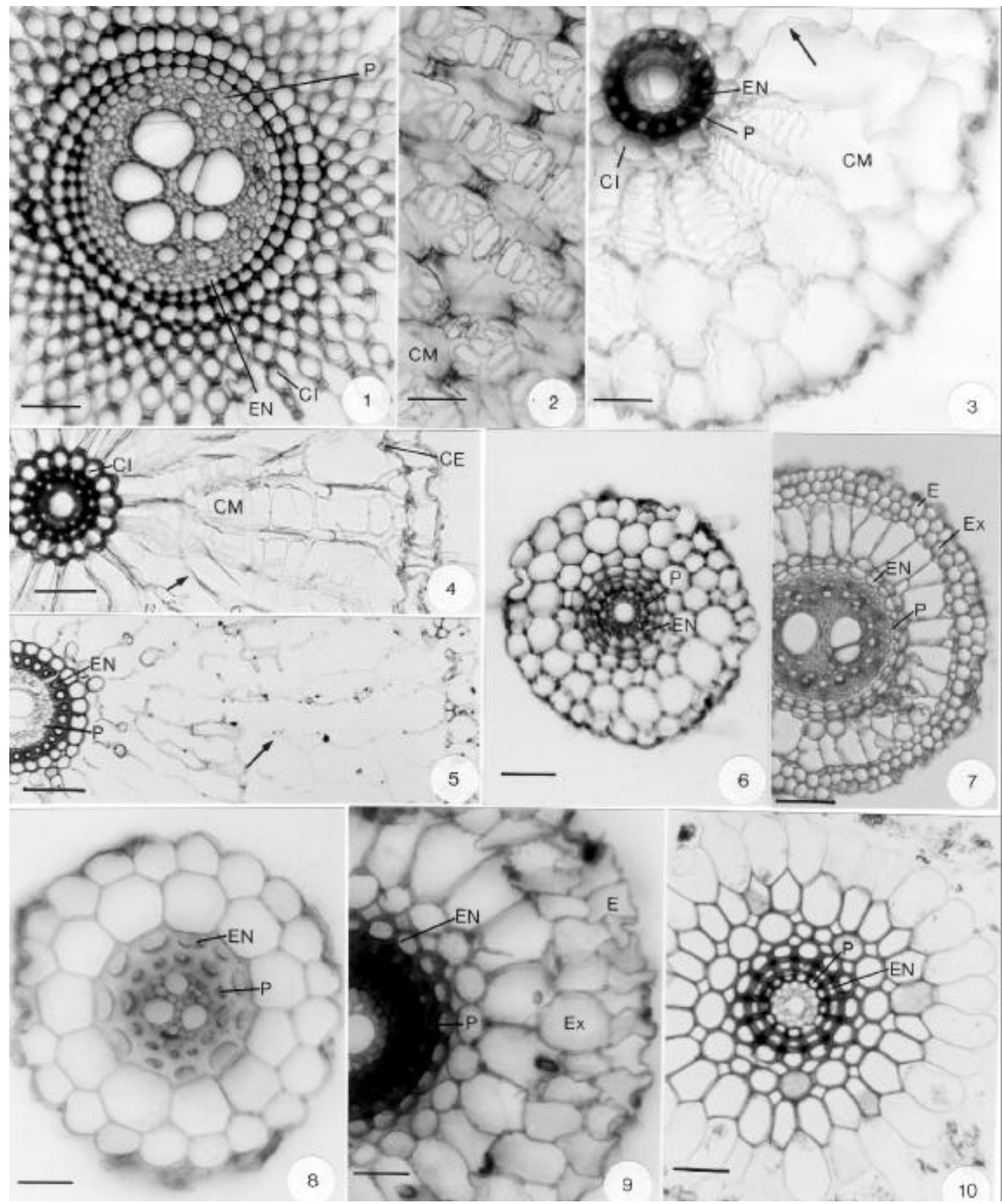

Fig. 1-10. Fotomicrografias das secções transversais das regiões medianas das raízes de Eriocaulaceae. 1-2. E. elichrysoides. 3. Ph. hoffmannseggii. 4. S. caulescens. 5. P. obtusifolius - raiz basal (absorvente). 6. P. obtusifolius - raiz adventícia (fixadora). 7. T. fluviatilis - raiz basal (absorvente). 8. T. fluviatilis - raiz adventícia (fixadora). 9. L. fluitans - raiz basal

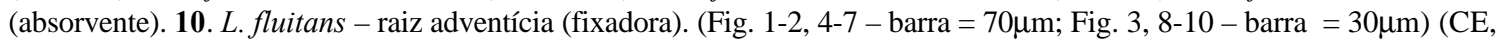
córtex externo; CI, córtex interno; CM, córtex médio; E, epiderme; EN, endoderme; Ex, exoderme; P, periciclo). 
Nas raízes fixadoras de $L$. fluitans (Fig. 10) a epiderme é a camada mais externa, formada por células de paredes finas, alongadas radialmente, e apresentam pêlos absorventes.

Em T. fluviatilis o caule é prostrado, flutuante, e as raízes que se distribuem ao longo dele (adventícias), muitas vezes não ficam em contato direto com a água, tendo sua função voltada principalmente à fixação. Aquelas raízes que crescem na base do caule, que permanecem em contato direto com o solo úmido do leito do rio, têm sua função voltada principalmente à absorção.

E. elichrysoides (Fig. 2) apresenta células braciformes do córtex mediano com braços curtos e numerosos, enquanto que $P h$. hoffmannseggii, S. caulescens e P. obtusifolius (Fig. 3-5 respectivamente) apresentam as células braciformes com braços longos e pouco numerosos. As células do córtex interno em $P h$. hoffmannseggii (Fig. 3), S. caulescens (Fig. 4), P. obtusifolius (Fig. 5), T. fluviatilis (Fig. 7) e $L$. fluitans (Fig. 9) são constituídas de uma única camada de células isodiamétricas, com paredes levemente espessadas, enquanto que em $E$. elichrysoides (Fig. 1) são constituídas de várias camadas de células arredondadas.

A endoderme é unisseriada de paredes finas como em E. elichrysoides (Fig. 1) e nas raízes adventícias de P. obtusifolius (Fig. 6). Pode apresentar-se espessada como em $P h$. hoffmannseggii (Fig. 3), S. caulescens (Fig. 4), nas raízes basais de $P$. obtusifolius (Fig. 5), e em ambos os tipos de raízes de T. fluviatilis (Fig. 7-8) e de L. fluitans (Fig. 9-10). Em E. elichrysoides (Fig. 1) a endoderme é a camada mais interna do córtex interno e dispõem-se de forma helicoidal. Em T. fluviatilis (Fig. 7) a raiz basal apresenta a endoderme com células de paredes espessadas em forma de "U". Não foram observadas estrias de Caspary nas células endodérmicas.

O periciclo é unisseriado, com células de paredes finas, podendo ser interrompido por elementos de protoxilema que tocam diretamente a endoderme em algumas espécies, como em $P$. obtusifolius (Fig. 5) e L. fluitans (Fig. 10). Em T. fluviatilis (Fig. 7) o periciclo é multisseriado, com células de paredes espessadas. O número de elementos de metaxilema do cilindro vascular varia nas diferentes espécies: em $P h$. hoffmannseggii (Fig. 3), S. caulescens (Fig. 4) e em L. fluitans (Fig. 9-10) há um único elemento central; enquanto que em P. obtusifolius (Fig. 5) e T. fluviatilis (Fig. 7-8) há dois ou três elementos centrais e em E. elichrysoides (Fig. 1) há vários elementos centrais de metaxilema. Em todas as espécies estudadas o floema é reduzido.

Caules - Os caules das espécies estudadas apresentam dois padrões anatômicos distintos: aqueles com a presença de endoderme e periciclo unisseriados, nas espécies que possuem caule aéreo sem espessamento suplementar e com entrenós distintos, como em $S$. caulescens (Fig. 11), Ph. hoffmannseggii (Fig. 12), T. fluviatilis (Fig. 13) e P. obtusifolius (Fig. 17); e aqueles com a presença de espessamento do órgão causado pelas divisões do periciclo que ocorre em espécies rizomatosas, como em L. fluitans (Fig. 14) e $E$. elichrysoides (Fig. 15-16).

Os caules das espécies estudadas apresentam epiderme unisseriada com células de paredes finas. O córtex pode apresentar-se homogêneo, caracterizado por várias camadas de células parenquimáticas de paredes finas, como pode ser observado em $T$. fluviatilis (Fig. 13), E. elichrysoides (Fig. 15-16) e $P$. obtusifolius (Fig. 17). Pode apresentar-se heterogêneo, como em S. caulescens (Fig. 11) e Ph. hoffmannseggii (Fig. 12), onde observase o córtex externo, com 1-2 camadas de células de paredes finas; o córtex médio, com células parenquimáticas de paredes finas e com aerênquimas lisígenos; e o córtex interno, com 1-2 camadas de células de paredes ligeiramente espessadas, sem espaços intercelulares. 
A endoderme pode apresentar-se unisseriada, com células de paredes espessadas, como em S. caulescens (Fig. 11), Ph. hoffmannseggii (Fig. 12), L. fluitans (Fig. 14) e P. obtusifolius (Fig. 17), ou com células de paredes finas, como em E. elichrysoides (Fig. 15). Na figura 13 , a endoderme de $T$. fluviatilis pode ser evidenciada pela coloração mais intensa das paredes de suas células, que são levemente espessadas, em relação às demais células do córtex. Não foram observadas estrias de Caspary nas células endodérmicas das espécies estudadas.

O periciclo é constituído por células de paredes espessadas (Fig. 11-12) ou finas (Fig. 13-17). O cilindro vascular apresenta feixes vasculares anfivasais em todas as espécies. Em $S$. caulescens, Ph. hoffmannseggii e em $T$. fluviatilis os feixes vasculares distribuem-se de maneira cilíndrica e periférica formando uma fileira, com medula bem evidente (Fig. 11-13 respectivamente); enquanto que nas demais espécies, os feixes vasculares distribuem-se de maneira mais concentrada, formando várias fileiras (Fig. 14-17). Pode-se observar feixes vasculares colaterais corticais em $E$. elichrysoides (Fig. 15) e P. obtusifolius (Fig. 17). A medula é constituída de células parenquimáticas de paredes finas em todas as espécies (Fig. 11-17).

Folhas - Nota-se semelhança no padrão anatômico do mesofilo na maioria das espécies estudadas, que apresenta-se composto por feixes vasculares que são intercalados por regiões de parênquima clorofiliano frouxo, com lacunas de ar (Fig. 18-24).

A epiderme é unisseriada, com células de paredes finas (Fig. 18-24) e formato tabular (longas no sentido longitudinal). Na face adaxial, as células são relativamente mais alongadas no sentido longitudinal e maiores quando comparadas com aquelas da face abaxial (Fig. 18-19, 21-24), com exceção de L. fluitans (Fig. 20), que apresenta células do mesmo tamanho em ambas as faces . As folhas apresentam bordo agudo (Fig. 21, 23) a levemente obtuso (Fig. 1820, 22, 24), com parênquima clorofiliano situado logo abaixo da epiderme, sem a ocorrência de tecido de sustentação. Em E. elichrysoides (Fig. 21) o bordo é formado pela junção das duas faces da epiderme. Em L. fluitans (Fig. 20) as células do bordo apresentam as paredes celulares levemente espessadas.

Os estômatos só ocorrem na face abaxial (Fig. 18-22, 24). Todavia, em S. caulescens os estômatos podem ocorrer também na face adaxial, próximos dos bordos da folha (Fig. 23). Em $L$. fluitans (Fig. 20) e E. elichrysoides (Fig. 21) as células estomáticas encontram-se no mesmo nível das demais células epidérmicas; enquanto que nas demais espécies estudadas, as células estomáticas situam-se no nível acima das demais células da epiderme (Fig. 18-19, 22-24).

O mesofilo é constituído por parênquima clorofiliano frouxo que, voltado para a face adaxial da epiderme, apresenta uma camada de células de parênquima paliçádico e, voltado para a face abaxial, apresenta 3-4 camadas de células de parênquima esponjoso na maioria das espécies, sendo que todas elas apresentam lacunas de ar (Fig. 18-24). Em Ph. hoffmannseggii (Fig. 18) e E. elichrysoides (Fig. 21) ocorre uma camada de parênquima regular voltada para a face adaxial e outra voltada para a face abaxial. Estas camadas delimitam a lacuna aerífera. Em L. fluitans (Fig. 20) o parênquima clorofiliano apresenta-se homogêneo, constituído por células levemente arredondadas.

Todas as folhas apresentam descontinuidade do parênquima, devido à presença de extensões de bainha dos feixes vasculares (Fig. 18-24), principalmente nos feixes maiores. Os feixes vasculares das folhas são colaterais e apresentam-se em número reduzido na maioria das espécies estudadas, exceto em $E$. elichrysoides (Fig. 21). L. fluitans (Fig. 20) pode apresentar apenas um único feixe vascular. Os 


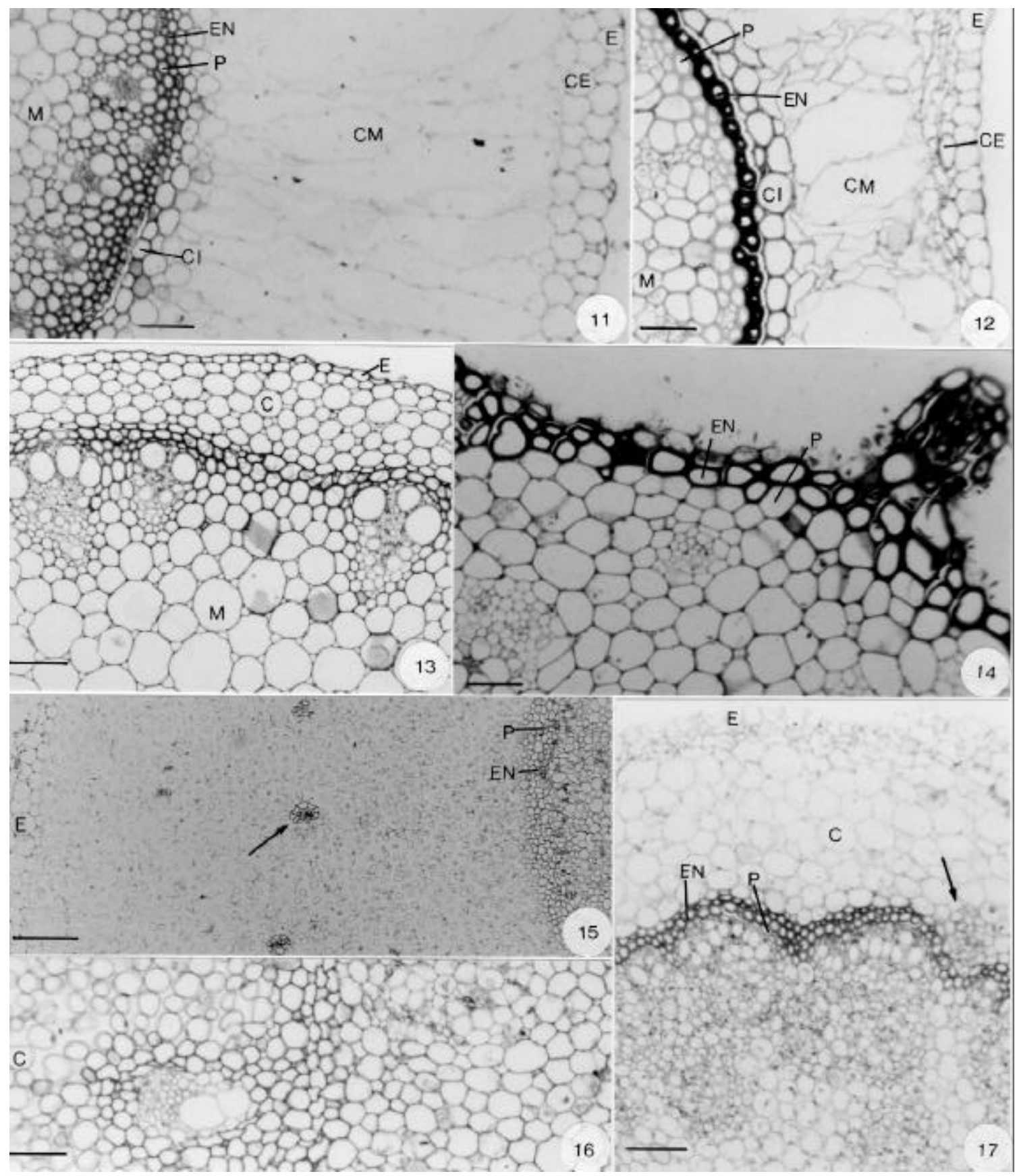

Fig. 11-17. Fotomicrografias das secções transversais nas regiões medianas dos caules de Eriocaulaceae. 11. S. caulescens. 12. Ph. hoffmannseggii. 13. T. fluviatilis. 14. L. fluitans. 15-16. E. elichrysoides. 17. P. obtusifolius. (Fig. 11, 13, 16-17 - barra $=70 \mu \mathrm{m}$; Fig. 12, 14 - barra $=30 \mu \mathrm{m}$; Fig. $15-$ barra $=200 \mu \mathrm{m})(\mathrm{C}$, córtex; CE, córtex externo; CI, córtex interno; CM, córtex médio; E, epiderme; EN, endoderme; M, medula; $\mathrm{P}$, periciclo) (seta: feixe vascular cortical). 


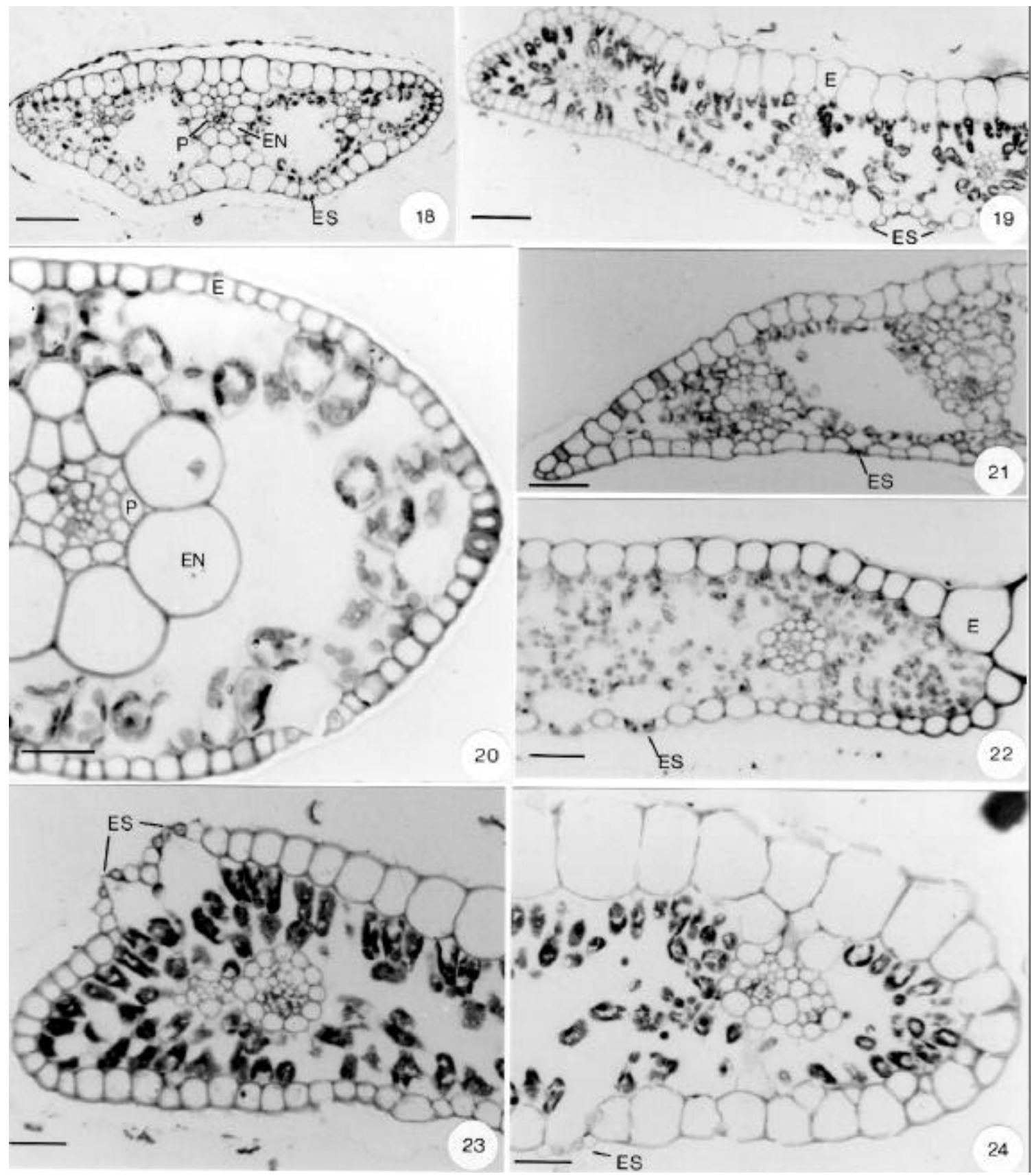

Fig. 18-24. Fotomicrografias das secções transversais nas regiões medianas das folhas de Eriocaulaceae. 18. $P h$. hoffmannseggii. 19, 23. S. caulescens. 20. L. fluitans. 21. E. elichrysoides. 22. T. fluviatilis. 24. P. obtusifolius. (Fig. 1819, $21-$ barra $=70 \mu \mathrm{m}$; Fig. $20-$ barra $=20 \mu \mathrm{m}$; Fig. $22-24-$ barra $=30 \mu \mathrm{m})($ E, epiderme; EN, endoderme; ES, estômato; P, periciclo). 
feixes maiores são envolvidos externamente pela endoderme e internamente pelo periciclo.

Escapos - Os escapos das espécies estudadas apresentam padrão anatômico semelhante, com a presença de epiderme, córtex e cilindro vascular (Fig. 25-30). A forma dos escapos varia de triangular (Fig. 28) a cilíndrica (Fig. 30).

A epiderme é unisseriada, formada por células de paredes finas (Fig. 25-29) ou ligeiramente espessadas (Fig. 30). Os estômatos apresentam-se restritos à região da epiderme situada sobre o parênquima clorofiliano (Fig. 25-30). O córtex é constituído por algumas camadas de células de colênquima situadas mais perifericamente e/ou parênquima regular, alternados por parênquima clorofiliano, separados topograficamente e que, no conjunto, formam uma estrutura radiada (Fig. 25-30).

O parênquima clorofiliano é constituído por células de parênquima paliçádico ou regular voltadas à periferia e por várias células de parênquima lacunoso na posição mais central (Fig. 25-30). Em todas as espécies estudadas, o parênquima clorofiliano apresenta lacunas de ar, semelhantes àquelas encontradas nas folhas das respectivas espécies (Fig. 25-30). Os escapos de $P$. obtusifolius, $S$. caulescens, E. elichrysoides e L. fluitans apresentam 2-3 camadas de colênquima, localizadas na periferia do órgão e parênquima localizado mais internamente, em direção ao cilindro vascular (Fig. 26, 28-30 respectivamente). As demais espécies apresentam apenas parênquima em toda sua extensão.

A endoderme apresenta-se contínua e cilíndrica, envolvendo todos os feixes vasculares, como em E. elichrysoides (Fig. 29) e L. fluitans (Fig. 30), ou apresenta-se descontínua, formando calotas apenas nos feixes vasculares menores, como em $T$. fluviatilis, P. obtusifolius, Ph. hoffmannseggii e $S$. caulescens (Fig. 25-28 respectivamente). Internamente à endoderme está o periciclo, que apresenta-se sinuoso, estrelado, isolando para fora os feixes vasculares menores e formando calotas sobre os maiores em todas as espécies estudadas (Fig. 25-30). Os feixes vasculares são colaterais, com elementos de metaxilema bem desenvolvidos. A medula é formada por células parenquimáticas de paredes finas (Fig. 25-30).

\section{Discussão}

Segundo Van Steenis (1957) e Sculthorpe (1967), as plantas aquáticas normalmente apresentam variações fenotípicas notáveis, incluindo modificações nas estruturas caulinares e foliares. Assim, muitas plantas têm o seu desenvolvimento diretamente associado às variações do ambiente em que se encontram. Nas Eriocaulaceae aquáticas estudadas neste trabalho foram observadas variações fenotípicas, relacionadas ao tamanho dos caules e das folhas. Observou-se uma convergência das estruturas anatômicas associadas ao ambiente aquático, nos diferentes órgãos, como: tecidos com células de paredes finas, presença de lacunas de ar, parênquima clorofiliano frouxo e tecidos vasculares reduzidos.

Segundo Malmanche (1919) e Tomlinson (1969), pode-se distinguir dois tipos básicos de raízes na família Eriocaulaceae: as vermiformes ou articuladas, com diafragmas corticais, que reservam ar, e as uniformes, não-vermiformes, sem diafragmas corticais, que não reservam ar.

As raízes de Eriocaulaceae que possuem córtex com diafragmas corticais formados por diferentes tipos de células, reservando ar, foram observadas por Malmanche (1919), Hare (1950), Tomlinson (1969), Giulietti (1978a; 1997), Stützel (1988), Scatena (1990), Scatena \& Rocha (1995), Scatena \& Menezes (1996a) e Scatena et al. (1999) em espécies aquáticas ou de locais úmidos de diferentes gêneros, principalmente em Eriocaulon, Leiothrix, Paepalanthus e Syngonanthus. 

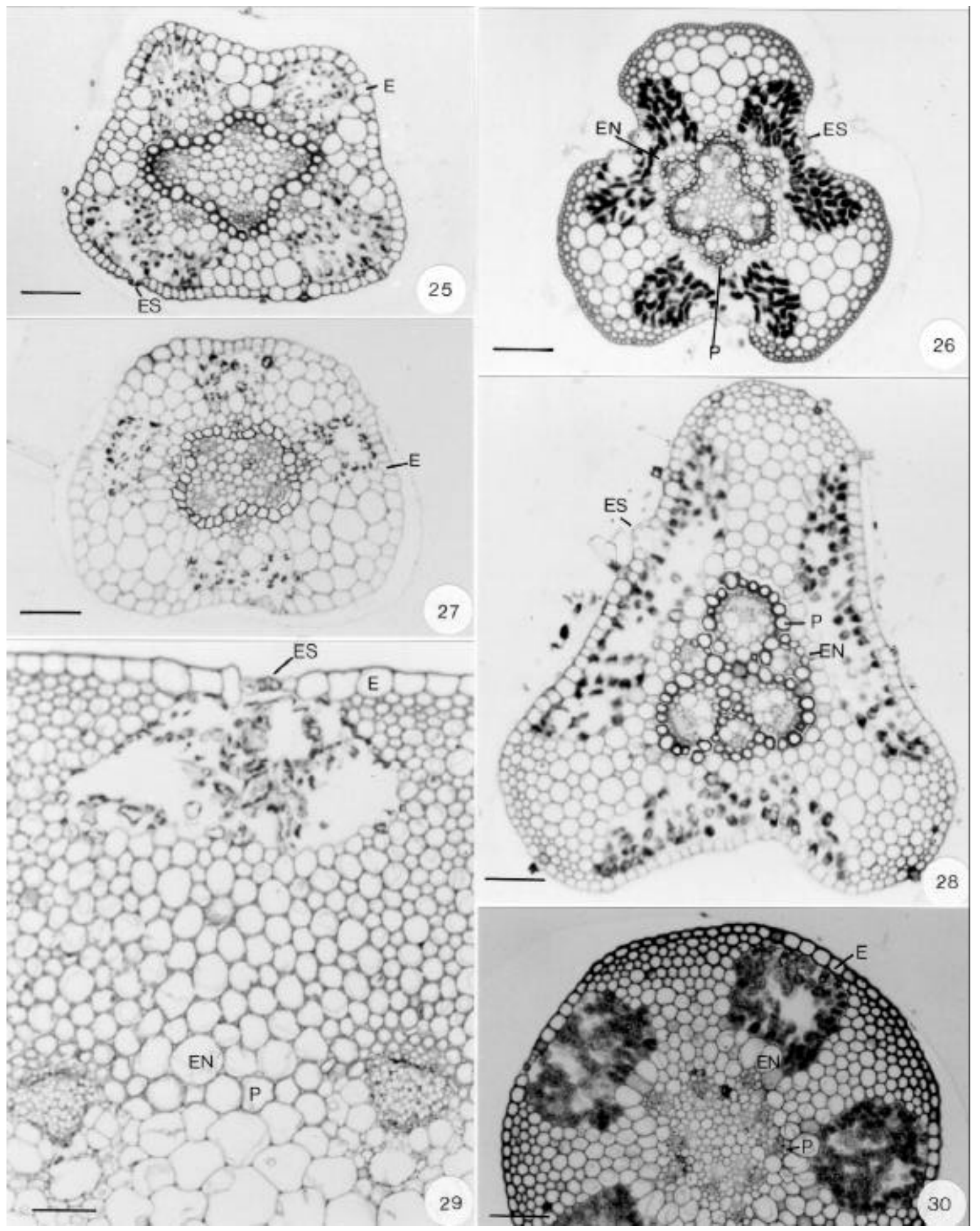

Fig. 25-30. Fotomicrografias das secções transversais nas regiões medianas dos escapos de Eriocaulaceae. 25. T. fluviatilis. 26. P. obtusifolius. 27. Ph. hoffmannseggii. 28. S. caulescens. 29. E. elichrysoides. 30. L. fluitans. (Fig. 25-30 - barra = $70 \mu \mathrm{m})(\mathrm{E}$, epiderme; EN, endoderme; ES, estômato; P, periciclo). 
Nas espécies estudadas neste trabalho observou-se que todas elas apresentam raízes com acúmulo de ar no córtex e células braciformes. Os braços dessas células são curtos e numerosos em E. elichrysoides, enquanto que nas demais espécies eles são longos e pouco numerosos. Talvez esse estado de caráter possa ser utilizado na taxonomia ou filogenia do grupo.

Como foi discutido por Scatena \& Menezes (1996a) para espécies de Syngonanthus, também para as espécies estudadas neste trabalho, o acúmulo de ar no parênquima cortical deve estar relacionado ao estresse hídrico ao qual a planta está exposta, com o excesso de água levando à diminuição do oxigênio, o que resulta na maior produção de etileno no ápice dessas raízes. Esse aumento na produção de etileno estimula a produção de celulase, levando à desintegração das paredes celulares (Moore 1979), formando espaços que reservam ar.

Para as raízes que não acumulam ar no parênquima cortical, Scatena \& Menezes (1996a) relacionam o fato de crescerem em locais onde o solo não permanece encharcado por muito tempo, não permitindo assim a atuação do etileno na formação de estruturas que acumulam ar. Deste modo, a presença ou não desses diafragmas está relacionada ao ambiente em que a planta cresce. Stützel (1988) infere que as espécies que formam o parênquima cortical com aerênquima são aquelas que crescem em solos encharcados, o que pode ser confirmado com os resultados obtidos no presente trabalho.

Vários são os estudos relacionados à formação do tecido aerenquimatoso nos órgãos vegetativos de diferentes espécies vegetais. Schussler \& Longstreth (2000), estudando a formação de aerênquima nas raízes de Sagittaria lancifolia (Alismataceae), relacionaram a lise das células corticais a um tipo de morte celular programada (PCD - programmed cell death). Esses autores também observaram essa característica em estágios avançados do desenvolvimento de Zea mays e Oriza sativa.
Os mesmos autores reforçam a idéia de que existem diferenças notáveis entre as espécies vegetais no que diz respeito aos mecanismos que levam à formação de espaços que reservam ar. Estudos concernentes à formação desses aerênquimas em espécies de Eriocaulaceae são necessários para se compreender os mecanismos que produzem essa importante adaptação a ambientes alagados.

Já era previsto que as espécies estudadas neste trabalho apresentassem raízes com acúmulo de ar no córtex, como resposta adaptativa ao ambiente aquático. Inédito para a família foi a ocorrência de dois tipos distintos de raízes no mesmo indivíduo como em $L$. fluitans, $P$. obtusifolius e $T$. fluviatilis: aquelas que acumulam ar no córtex e aquelas que não acumulam ar. A ocorrência desses dois tipos de raízes no mesmo indivíduo pode ser explicada pelo hábito da planta.

O hábito em $T$. fluviatilis pode ser comparado ao que foi estudado em Eriocaulon melanocephalum por Giulietti (1978b), que cresce na beira de riachos ou em poças de água temporárias. De acordo com a autora, há relação entre a mudança de hábito das plantas e o nível de água das poças e dos riachos. Desse modo, na medida em que o nível de água se reduz, os indivíduos encostam-se no substrato, devido à flexibilidade de seus caules. Assim, novas raízes são originadas da região caulinar, até mesmo próximas aos escapos, desempenhando a função de fixação da planta ao substrato. O mesmo deve ocorrer também com $P$. obtusifolius que cresce nas margens dos riachos.

L. fluitans cresce no leito de pequenos rios e apresenta algumas raízes que se aderem firmemente ao substrato rochoso desses riachos e das cachoeiras, de onde são dificilmente destacadas (Giulietti 1978a; Giulietti \& Hensold 1990). Observou-se neste trabalho que, além dessas raízes que fixam a planta ao substrato rochoso, ocorrem outras distribuídas ao longo do rizoma, que têm a função voltada 
principalmente para a absorção, sendo de coloração mais clara e textura menos rígida. Considera-se que a capacidade de formação de dois tipos de raízes no mesmo indivíduo esteja associada ao padrão morfológico da planta, regulada por fatores genéticos, porém a sua ocorrência ou não vai estar regulada por fatores ambientais externos.

Tomlinson (1969) reconhece nas raízes de Eriocaulaceae três zonas corticais distintas. Neste trabalho, observou-se principalmente em E. elichrysoides que as camadas corticais internas, dispostas em fileiras radiais, com pequenos espaços intercelulares, originam-se da endoderme meristemática, conforme foi demonstrado por Van Fleet (1961) e por Menezes et al. (comunicação pessoal).

De acordo com Giulietti (1978b), os diferentes padrões morfológicos nos caules das Eriocaulaceae e a ocorrência de padrões similares em gêneros distintos, dizem respeito à utilização pelas espécies de diferentes estratégias em resposta ao ambiente. Segundo a autora, os padrões similares estariam mais associados ao tipo de ambiente onde as plantas ocorrem do que ao grupo taxonômico a que pertencem.

Seguindo essa linha de raciocínio $P h$. hoffmannseggii, S. caulescens, P. obtusifolius e T. fluviatilis apresentam caules aéreos com entrenós distintos, sendo que nas duas primeiras espécies o córtex apresenta grandes espaços de ar, constituindo um aerênquima lisígeno, como ocorre nas raízes. Essa semelhança entre espécies de gêneros diferentes certamente está associada ao ambiente onde elas ocorrem, com muita disponibilidade de água.

Nas espécies que apresentam caules do tipo rizoma, como em E. elichrysoides e L. fluitans, a endoderme meristemática forma o córtex interno multisseriado, sendo que a endoderme é a camada mais interna desse córtex interno, seguindo os estudos de Menezes et al. (comunicação pessoal) com várias outras monocotiledôneas.
Nas espécies estudadas neste trabalho, o aerênquima é bem desenvolvido e interceptado por diafragmas transversais. A presença de aerênquima e diafragmas é geralmente observada em plantas que crescem em ambientes aquáticos ou muito úmidos, e não há dúvida sobre a sua importância para a fisiologia da planta, principalmente na maior eficiência das trocas gasosas (Sculthorpe 1967; Kaul 1971; Esau 1977; Fahn 1982). A principal função de um tecido aerenquimatoso altamente compartimentado em plantas aquáticas é a estabilidade mecânica (Williams \& Barber 1961). Esses autores consideram que nesse tecido aerenquimatoso fica preservado um mínimo de oxigênio requerido de um ambiente aquático, pobre em oxigênio, e que os canais de ar nas partes aéreas das plantas aquáticas suprem o oxigênio para as raízes. Desse modo, a presença de aerênquimas nos diferentes órgãos das espécies estudadas, representa uma adaptação dessas plantas ao ambiente aquático e/ou anfíbio.

Todas as espécies estudadas neste trabalho apresentam folhas sem tecidos de sustentação, como proposto por Esau (1977) e Fahn (1982) para as plantas aquáticas em geral. O que contrapõe com as demais espécies dos diferentes gêneros de Eriocaulaceae estudadas por Scatena \& Rocha (1995), Scatena \& Menezes (1996b) e Scatena \& Moraes (1996) em que a presença de tecido de sustentação nas folhas é marcante. Estas plantas crescem no ambiente terrestre, são expostas a ventos constantes, intensidade luminosa alta e estresse hídrico (falta de água), pelo menos em parte do ano.

Os feixes vasculares das folhas são colaterais, envolvidos externamente pela endoderme e internamente pelo periciclo, correspondendo às bainhas externa e interna respectivamente. Segundo Tomlinson (1969), Giulietti (1978a; 1997), Monteiro et al. (1985) e Scatena \& Menezes (1996b), os feixes vasculares envolvidos por bainha dupla são 
considerados característicos das espécies de Eriocaulaceae.

As características anatômicas das folhas das espécies estudadas como: epiderme com células de paredes finas, ausência de tecido de sustentação, presença de lacunas de ar, número reduzido de feixes vasculares (com exceção de E. elichrysoides cujas folhas ficam totalmente emersas) e elementos vasculares pouco desenvolvidos são marcantes de espécies aquáticas ou de locais úmidos, com alta disponibilidade de água.

Em relação aos escapos, as espécies estudadas apresentam a localização espacial dos tecidos semelhante às demais espécies dos diferentes gêneros de Eriocaulaceae já estudadas. As diferenças observadas consistem na presença de células epidérmicas com paredes finas, na ausência de tecido de sustentação (esclerênquima) e na redução de elementos vasculares. Enquanto que nas demais espécies de diferentes gêneros já estudadas, é marcante o espessamento das paredes das células epidérmicas, presença maciça de tecido de sustentação e elementos vasculares bem desenvolvidos, o que está de acordo com o ambiente terrestre onde crescem em condições estressantes (Scatena \& Menezes 1996b; Scatena $\&$ Moraes 1996; Scatena \& Rosa 2001).

O córtex apresenta raio cortical constituído por tecido de sustentação pouco desenvolvido, o colênquima, que está localizado mais na periferia do órgão em E. elichrysoides, $L$. fluitans, P. obtusifolius e $S$. caulescens, e deve estar relacionado com o fato do escapo ser longo para sustentar o capítulo fora da água, enquanto que em Ph. hoffmannseggii e T. fluviatilis, o escapo é curto e o córtex é constituído apenas por parênquima, não apresentando nenhum tecido de sustentação.

Anatomicamente, as Eriocaulaceae aquáticas estudadas apresentam a estrutura básica encontrada em todas as outras espécies estudadas até então como: raízes com ou sem acúmulo de ar no parênquima cortical; caules com feixes vasculares anfivasais; folhas com epiderme apresentando estômatos somente na face abaxial e feixes vasculares colaterais envolvidos por endoderme e periciclo; e escapos com costelas e feixes vasculares colaterais. A presença de lacunas de ar nos diferentes órgãos deve estar relacionada com a manutenção da maior eficiência nas trocas gasosas, representando uma adaptação dessas plantas ao ambiente aquático.

Essas estruturas anatômicas são determinantes nas plantas de ambientes úmidos ou aquáticos, levando à convergência anatômica nos diferentes gêneros de Eriocaulaceae.

\section{Referências bibliográficas}

Esau, K. 1977. Anatomy of Seed Plants. John Wiley $\&$ Sons, New York.

Fahn, A. 1982. Plant Anatomy. Pergamon Press, New York.

Feder, N. \& O’Brien, T. P. 1968. Plant microtechnique: some principles and new methods. American Journal of Botany 55(1): 123-142.

Giulietti, A. M. 1978a. Os gêneros Eriocaulon L. e Leiothrix Ruhl. (Eriocaulaceae) na Serra do Cipó, Minas Gerais, Brasil. Tese de Doutorado. Universidade de São Paulo, São Paulo.

Giulietti, A. M. 1978b. Modificações taxonômicas no gênero Eriocaulon L. Boletim de Botânica da Universidade de São Paulo 6: 39-47.

Giulietti, A. M. 1997. Análise crítica da evolução da morfologia e da sistemática das Eriocaulaceae. Tese de Titular. Universidade Estadual de Feira de Santana, Feira de Santana.

Giulietti, A. M. \& Pirani, J. R. 1988. Patterns of geographic distribution of some plant species from the Espinhaço Range, Minas Gerais and Bahia, Brazil. Pp. 39-69. In: P. E. Vanzolini \& W. R. Heyer (Eds.). Proceedings of a workshop of neotropical distribution patterns. Academia Brasileira de Ciências, Rio de Janeiro.

Giulietti, A. M. \& Hensold, N. 1990. Padrões de distribuição geográfica dos gêneros de Eriocaulaceae. Acta Botanica Brasilica 4(1): 133-159.

Giulietti, A. M.; Amaral, M. C. E. \& Bittrich, V. 1995. Phylogenetic analysis of inter- and infrageneric relationships of Leiothrix Ruhland (Eriocaulaceae). 
Kew Bulletin 50(1): 55-71.

Giulietti, A. M.; Menezes, N. L.; Pirani, J. R.; Meguro, M. \& Wanderley, M. G. L. 1987. Flora da Serra do Cipó, Minas Gerais: caracterização e lista das espécies. Boletim de Botânica da Universidade de São Paulo 9: 1-151.

Hare, L. C. 1950. The structure and development of Eriocaulon septangulare With. Botanical Journal of the Linnean Society 53: 422-448.

Johansen, D. A. 1940. Plant microthechnique. Mc Grall-Hill Book Co., New York.

Kaul, R. B. 1971. Diaphragms and aerenchyma in Scirpus validus. American Journal of Botany 58: 808-816.

Lazzari, L. R. P. 1995. Syngonanthus Ruhland (Eriocaulaceae) na Serra do Cipó, Minas Gerais, Brasil. Dissertação de Mestrado. Universidade de São Paulo, São Paulo.

Malmanche, L. A. 1919. Contribution à l'étude anatomique des Eriocaulacées et des families voisines: Restiacées, Centrolépidacées, Xyridacées, Philydracées, Mayacacées. Thesis. St. Cloud, Paris.

Monteiro, W. R.; Castro, M. M. \& Giulietti, A. M. 1985. Aspects of leaf structure of some species of Leiothrix Ruhl. (Eriocaulaceae) from the Serra do Cipó (Minas Gerais, Brasil). Revista Brasileira de Botânica 8: 109-125.

Moore, T. C. 1979. Biochemistry and Physiology of Plant Hormones. Thomas C. Moore, New York.

Roeser, K. R. 1962. Die nadel der schwarzkiefermassenprodukt und kunstwert der natur. Mikrokosmos 61: 33-36.

Ruhland, W. 1903. Eriocaulaceae. In: A. Engler (Ed.). Das Pflanzenreich. IV, 30: 1-294. Wilhelm Engelmann, Leipzig.

Scatena, V. L. 1990. Morfo-anatomia de espécies de Syngonanthus Ruhl. (Eriocaulaceae) dos campos rupestres do Brasil. Tese de Doutorado. Universidade de São Paulo, São Paulo.

Scatena, V. L. \& Rocha, C. L. M. 1995. Anatomia dos órgãos vegetativos e do escapo floral de Leiothrix crassifolia (Bong.) Ruhl., Eriocaulaceae, da Serra do Cipó - MG. Acta Botanica Brasilica 9(2): 195-211.
Scatena, V. L. \& Menezes, N. L. 1996a. Anatomia de raízes de Syngonanthus Ruhl. (Eriocaulaceae). Revista Brasileira de Biologia 56(2): 333-343.

Scatena, V. L. \& Menezes, N. L. 1996b. Anatomia de escapos e folhas de Syngonanthus Ruhl. (Eriocaulaceae) de campos rupestres. Revista Brasileira de Biologia 56(2): 317-332.

Scatena, V. L. \& Moraes, A. R. S. 1996. Anatomia de raízes, folhas e escapos de espécies de Paepalanthus subgênero Platycaulon (Eriocaulaceae). Arquivos de Biologia e Tecnologia 39(4): 1021-1035.

Scatena, V. L. \& Rosa, M. M. 2001, Morphology and anatomy of the vegetative organs and scapes from Aphorocaulon (Paepalanthus, Eriocaulaceae). Brazilian Archives of Biology and Technology 44(1): 49-58.

Scatena, V. L.; Giulietti, A. M. \& Cardoso, V. A. 1998. Anatomia do escapo floral de espécies brasileiras de Paepalanthus subgênero Platycaulon (Eriocaulaceae). Acta Botanica Brasilica 12(2): 121-133.

Scatena, V. L.; Giulietti, A. M. \& Cardoso, V. A. 1999. Anatomia de raízes, escapos e folhas de espécies de Eriocaulon L. (Eriocaulaceae). Boletim de Botânica da Universidade de São Paulo 18: 11-20.

Schussler, E. E. \& Longstreth, D. J. 2000. Changes in cell structure during the formation of root aerenchyma in Sagittaria lancifolia (Alismataceae). American Journal of Botany 87(1): 12-19.

Sculthorpe, C. D. 1967. The Biology of Aquatic Vascular Plants. Edward Arnold, London.

Stützel, T. 1988. Untersuchungen zur wurzelanatomie der Eriocaulaceen. Flora 180: 223-239.

Tomlinson, P. B. 1969. Commelinales-Zingiberales. In: C. R. Metcalfe (Ed.). Anatomy of the Monocotyledons. Clarendon Press, v.3, Oxford.

Van Fleet, D. S. 1961. Histochemistry and function of the endodermis. The Botanical Review 27(2): 165-220.

Van Steenis, C. G. G. 1957. Specific and intraspecific delimitation. Flora Malasiana 1(53): 167-234.

Williams, W. T. \& Barber, D. A. 1961. The functional significance of aerenchyma in plants. Symposium of the Society of Experimental Biology 15: 134144. 